\section{Bone, bones and biomechanics}

\author{
Charles E. Oxnard
}

The Mechanical Adaptations of Bones. By John Currey.

Princeton University Press: 1984. Pp.294. $\$ 37.50$, £37.20.

FOR earlier generations, D'Arcy Thompson's On Growth and Form (published in 1917) and P.D.F. Murray's Bones (1934) provided the critical descriptions of what was then known about biomechanics and the mechanical adaption of bone. Nearer our own time, F. Gaynor Evans's Stress and Strain in Bone (1957) both provided a summary of the exciting if somewhat confused earlier investigations and marked the beginning of new research based upon the insights of modern engineering. John Currey's book is the natural current successor, together with McNeill Alexander's 1968 and 1984 editions of Animal Mechanics, and Wainright, Biggs, Currey and Gosline's Mechanical Design in Organisms (1976). Each of these books supplies its own commentary on the general subject, but, although there is inevitably some overlap, they concentrate upon different facets of the field and are aimed at different readerships.

Much of the early work, often dating from the last century and important though it is, confused stress, strain and architecture; the new investigations described by Currey do not. The old studies followed engineering strength-of-materials traditions by presenting biological materials, especially bone, as though they were homogeneous, isotropic and perfectly elastic bodies capable of being described through infinite beam theory. Currey discusses the new approaches which acknowledge that, like many non-organic materials, bone is inhomogeneous, nonisotropic and demonstrates imperfectly elastic, poroelastic and plastic-elastic properties, and each at several different microscopic levels. In particular, these approaches imply that stress in bones, especially irregular bones and the oddshaped ends of long bones, is better characterized through techniques such as finite element analysis.

Currey recognizes that all bone and all bones are not alike, and gives many examples of how different types of bone and different designs of bones serve differing functions. He discusses, for instance, differences in form and physical properties of bone ranging from the brittleness and stiffness of the auditory elements in whales related to the transmission of sound in water to the curvatures of finger bones used to suspend the bodies of brachiating apes from branches.

In contrast to many other writings on this subject, Currey also describes not only immediate and ontogenetic bony adaptation, but takes into account the evolutionary perspective. He makes a convincing case for the design of bone by natural selection while recognizing phylogenetic constraints; and he considers the all-pervasive action of natural selection in producing optimum structure while emphasizing that all mechanical properties of biological materials are a compromise between conflicting requirements.

Perhaps most importantly of all, however, in this book Currey provides an introduction for biologists to the basic ideas of strength of materials and mechanics. This is a summary that should do much to remove misconceptions that still remain in the minds of some students and even some investigators in this area. Among them are the idea that if one set of stress trajectories is compressive then the other must be tensile (which does not necessarily follow), that a limb under tension implies bone under tension (which it

\section{Light on polymers}

\section{Herbert Morawetz}

Polymer Photophysics and Photo-

chemistry: An Introduction to the Study of Photoprocesses in Macromolecules.

By James Guillet.

Cambridge University Press: 1985.

Pp.391. f45, \$79.50.

IN these days of extreme specialization, it is rare to find an author who is equally at home in photophysics and photochemistry. Thirty years ago James Guillet worked under Norrish's direction on a doctoral thesis dealing with the photodegradation of polymeric ketones. Since then, he has not only continued to be a leader in polymer photochemistry, but has made seminal contributions to the study of fluorescence and phosphorescence of polymers, both in solution and in bulk, and has published stimulating accounts of the "antenna effect" in which the energy absorbed by a small number of chromophores is relayed along a polymer chain to excite a group far removed from the absorption site. While Professor Guillet's hope that such a process would lead to a chemical reaction has not been realized so far, it is an exciting possibility which may well be demonstrated in the future.

Although areas in which Professor Guillet has been active are stressed more heavily in this his latest book, it does contain an excellent coverage of the field. The only major area I missed is the extensive Russian contribution to the study of polymers by emission anisotropy, which has been summarized by Anufrieva and Gotlib (Adv. Polym. Sci. 40, 1; 1981). The effect of the adsorption of fluorescent dyes on their emission characteristics might also have been mentioned. need not) and that mechanical stresses are chiefly borne by bone (they are not: the little known interior complexity of the muscle-tendon unit, and those even less understood and poorly described elements, fascial sheets and ligaments, are all important stress-bearing features especially in the larger land animals).

Finally, although Currey's book unhesitatingly simplifies the ideas of strength of materials in order to aid student understanding, it also reminds us, at almost every step, that real biological situations are much more complex; therein lies the future of these studies. The book is, thus, an excellent source of facts and ideas for students and a resource for their teachers, while at the same time providing a superb set of problems for investigators.

Charles E. Oxnard is University Professor and Professor of Anatomy and Biology at the University of Southern California. He is author of The Order of Man YYale University Press, 1984).

While the book is an outstanding introduction to photophysics and photochemistry for polymer scientists, I am less sure that the discussion of the principles of polymer science will be adequate for those unfamiliar with this field. There are a number of errors: the expansion coefficient $\alpha$ (p.33) is not treated as chain length dependent; rotational isomeric state calculations (p.34) depend little on the height of rotational barriers; there are no D) and L configurations in stereoregular vinyl polymers; the lamellar thickness of folded polymer chains (p.46) is of the order of $10 \mathrm{~nm}$ not $1000 \mathrm{~nm}$; it is not possible to estimate the intrinsic viscosity from measurements at a single concentration without knowledge of the "Huggins constant" (p.74); the spacing of phenyl groups in the helix of isotactic polystyrene is not "of the order of $3 \AA$ " but much too large for excimer formation (p.178); and Haas et al. and Sisido (p.230) did not study cyclization. It is also a pity that the references only run up to 1981 . But these are minor blemishes on a most useful book which is a valuable addition to the polymer literature.

Herbert Morawetz is a Professor in the Department of Chemistry at the Polytechnic Institute of New York.

\section{New in paperback}

- A single-volume edition of Christian de Duve's A Guided Tour of the Living Cell. Publisher is W. H. Freeman, price is $\$ 33.95$, £24.95. Sterling price of the hardback is $£ 35.90$ per two-volume set, not $£ 39.90$ as printed in the review (Nature 314, 694; 1985).

- Radiative Processes in Astrophysics by George B. Rybicki and Alan P. Lightman. Publisher is Wiley, price is $\$ 26.50, \mathfrak{2} 23$. For review see Nature 289, 729 (1981).

- In Search of Mind by Jerome Bruner. Publisher is Harper \& Row, price is $\$ 6.95, £ 7.75$. For review see Nature 308, 779 (1984). 